\title{
LXX. On some new aparatus for use in gas-analysis
}

\section{J. Alfred Wanklyn \& W.J. Cooper}

To cite this article: J. Alfred Wanklyn \& W.J. Cooper (1881) LXX. On some new aparatus for use in gas-analysis, Philosophical Magazine Series 5, 11:71, 534-536, DOI: 10.1080/14786448108627055

To link to this article: http://dx.doi.org/10.1080/14786448108627055

曲 Published online: 08 Jun 2010.

Submit your article to this journal ¿

山 Article views: 2

Q View related articles ¿ 
7th. That whenever energy is transferred from one body to another it is also always transformed from the potential to the kinetic form, or vice ver'ŝa.

8 th. That energy never changes its form without at the same time being transferred from one body to another by an act of work.

9th (and most important). That the term " body" includes every material thing, whether visible or ponderable or otherwise, and that a piece of matter is to be regarded as a different "body" from the ultimate particles of which it is composed; so that when a bullet strikes a target one may say that part of the energy of the bullet is transferred to its particles; and when a spring uncoils suddenly, that the energy of the strained particles is transferred to the mass of the spring-just as easily as one may say that, when a pendulum swings, energy is transferred from one "body," the gravitation medium, to another, the bob of the pendulum, or vice vers $\hat{a}$, at every quarter swing.

LXX. On some new Aparatus for use in Gas-analysis. By J. ALFRED WANKLYN and W. J. COOPER*.

THE analysis of gases by means of measurements over 1 mercury has been brought to a state of great perfection, and is admirably adapted for many purposes. Still there are instances in which this method of procedure is inapplicable.

Such instances are found in those cases where the constituent is very small in amount, or where the gas attacks mercury. There is a very familiar example in the carbonic acid of the atmosphere. Ten thousand volumes of air contain about four volumes of carbonic acid. If the chemist makes a measurement of air confined over mercury, and then absorbs the carbonic acid by potash, and then measures the air freed from carbonic acid, he obtains data from which he might propose to calculate the amount of carbonic acid in the air. But, as has been pointed out on various occasions by different chemists, these data lose their value because the experimental error is almost as large as the difference between the two gas-measurements. Determinations of the carbonic acid in atmospheric air carried out by this method are illusory; and long ago (so long ago as the beginning of the century) another method was resorted to.

The other method consists in exposing a known volume of air to the action of lime-water or baryta-water, and in noting

* Communicated by the Authors. 
the amount of change suffered by the lime- or baryta-water. Sometimes the amount of the insoluble carbonate is weighed, and sometimes the diminution of alkalinity is noted; and the characteristic of this method is that the point to be observed is the change in the reagent, and not in the volume of the gas.

In carrying out these measurements of the carbonic acid in the air the manipulation is of the simplest description. The air is contained in a large stoppered flask or bottle, the capacity of which has been measured. The stopper is taken out, the baryta-water is poured in, and the stopper is replaced. Then the bottle is shaken up for a sufficient length of time; and ultimately the operator takes the stopper out, and deals with the cartionate of baryta or the baryta-water in the wellknown manner.

Now let us suppose that the chemist had to measure the carbonic acid in a gas lighter than air. Ho has his bottle filled with, for example, coal-gas.

It will be apparent that when he tries to pour the barytawater into the gas he will meet with difficulties. If the mouth of the bottle be held upwards, the gas will escape when the stopper is removed; and, if the mouth be directed downwards, the operator will not be able to pour the baryta-water into the bottle.

Our new apparatus is designed to enable the operator to overcome this difficulty. Wo make the stopper hollow, and place the reagent in the stopper. Instead of a solid stopper we use a flask of thick glass, the neck of which is ground so as to fit into the neck of the gas-bottle.

The following examples will sorve to illustrate our method of operating :-

We had occasion to measure the carbonic acid, sulphuretted hydrogen, and ammonia in crude coal-gas-that is to say, in coal-gas from which the tar and water distilling with the tar had been removed, but which had not been further purified.

The gas in question was collected by displacement in a bottle holding 2750 cubic centim.; and about 50 cubic centim. of strong baryta-water was placed in the little flask which was employed instead of a stopper to close the bottle containing the gas. The apparatus was then shaken, and the resulting carbonate of baryta collected on a filter, washed, ignited, and weighed. From the amount of carbonate the amount of carbonic acid was calculated. In another experiment the sulphuretted hydrogen was measured by using a solution of acetate of lead, the sulphuret of lead being subsequently converted into sulphate of lead, and weighed. In a 
third experiment the ammonia was ascertained by the use of dilute standard acid.

The results are as follows :-In 1000 vols. of crude coalgas,

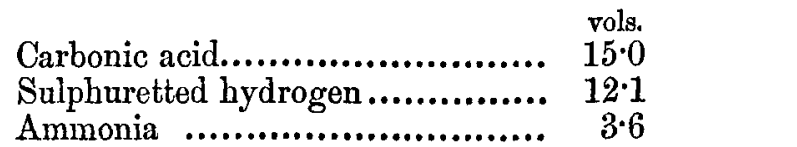

The apparatus possesses many practical advantages, which reveal themselves when the operator begins to use it. Thus, the reagent may be drained into the flask, removed from the gas, and a fresh quantity of reagent omployed. Successive treatment is even practicable to a certain extent.

\section{Notices respecting New Books.}

Miscellaneous Scientific Papers by W. J. Macquorn Rankine, C.E., LL.D., F.R.S., late Regius Professor of Civil Engineering and Mechanics in the University of Glasgow. From the Transactions and Proceedings of the Royal and other Scientific and Philosophical Societies, and the Scientific Journats. With a Memoir of the Author by P. G. TaIr, M.A. Edited by W. J. Mmxar, C.E. With Portrait, Plates, and Diagrams. London: Charles Griffin and Co., 1881. (Pp. xxxvi and 567.)

A FTER a considerable lapse of time(Rankine died December 24th, A 1872) these papers are now issued in a collected form. It is hard to account for so long a delay, seeing that the papers have all been published before, and we cannot suppose any hindrance was interposed by the governing bodies of the Scientific Societies and Journals to whom the papers were originally intrusted by the author. It is sufficient now for us to indicate how many and, to a certain extent, which of the 150 and more papers (cf. Royal Society Catalogue of Scientific Papers) are here submitted as worthy of fitly representing Rankine's contributions to science. Their number is thirty-seven, classed under three heads. The first group embraces those papers which relate to Temperature, Flasticity, and Expansion of Vapours, Liquids, and Solids. Of the nine papers, three first saw the light in our pages, viz.:-iii. "On the Centrifugal Theory of Elasticity, as applied to Gases and Vapours" (Dec. 1851); vii. "On the Vibrations of Plane-polarized Light" (June 1851); viii. "General View of an Oscillatory Theory of Light" (Dec. 1853). The longest paper (read before the British Association, August 1850 , and published in the Cambridge and Dublin Mathematical Journal, May 1851) is on the "Laws of the Elasticity of Solid Bodies." The second group contains papers relating to Energy and its Transformations, Thermodynamics, Mechanical Action of Heat in the Steam-engine, \&c.; they are nineteen in number. In this group also are three Phil. Mag. papers:- $x$. the remarkable paper 